\title{
Can lung function measurements be used to predict which patients will be at risk of developing interstitial pneumonitis after bone marrow transplantation?
}

Heather J Milburn, H G Prentice, R M du Bois

\begin{abstract}
Background Lung function often deteriorates after bone marrow transplantation for haematological malignancies. Whether pulmonary function measurements are useful for monitoring patients' progress after transplantation and for alerting clinicians to the development of pneumonitis is uncertain.
\end{abstract}

Methods Serial pulmonary function measurements were made in 39 patients with a haematological malignancy, and the values from 18 recipients of $T$ cell depleted allogeneic $(n=17)$ or autologous $(n=1)$ bone marrow transplants who developed interstitial pneumonitis were compared retrospectively with values from 21 recipients of allogeneic $(n=17)$ or autologous $(n=4)$ transplants who did not develop pneumonitis. Lung function was measured at the onset of a further 18 episodes of pneumonitis.

Results Measurements made before transplantation showed no difference in forced expiratory volume in one second $\left(F E V_{1}\right)$, transfer factor for carbon monoxide (TLCO), or total lung capacity between the two groups, but the forced vital capacity (FVC) was slightly higher in those who developed pneumonitis (mean (SD) \% predicted 104 (12)) than in those who did not $(93(17 \%))$. Six weeks and three months after transplantation all pulmonary function measurements had fallen slightly in both groups but TLco had fallen considerably more in those who later developed pneumonitis, being $71 \%$ (SD $11 \%$ ) and $77 \%(7 \%$ ) of pretransplant values in patients who later developed pneumonitis compared with $109 \%(38 \%)$ and $96 \%(26 \%)$ in those who did not. All lung function measurements were significantly lower at the onset of pneumonitis than three months after transplantation, even in patients with no abnormal signs and a normal chest radiograph.

Conclusions Serial measurements of gas transfer before and after bone marrow transplantation may be useful for predicting which patients will be at risk of developing pneumonitis and may help to diagnose pneumonitis in breathless patients with no abnormal signs.

Lung function may deteriorate in patients undergoing bone marrow transplantation, ${ }^{1}$ as a consequence of drug treatment, irradiation, infection, and graft versus host disease in addition to progression of disease. ${ }^{2-6}$ Patients with leukaemia and aplastic anaemia may show functional abnormalities ${ }^{17}$ in the absence of clinical signs of pulmonary disease. Both restrictive and obstructive changes have been described after bone marrow transplantation for haematological malignancies, ${ }^{7-17}$ and a reduction in gas transfer has also been reported. ${ }^{10}$ Patients with persistent obstructive defects usually also have chronic graft versus host disease ${ }^{811}$ and there is a reported association between acute and chronic graft versus host disease and bronchiolitis obliterans. ${ }^{12-14}$

In addition to cytotoxic chemotherapy that may be toxic to the lungs, many patients receiving allogeneic transplants in particular are given total body irradiation, which may cause lung damage. Total body radiation doses of the order of $1000 \mathrm{cGy}$ have been associated with increased vascular permeability, alveolar wall oedema, and alveolar protein leakage with gross loss of lung surfactant in animals, ${ }^{16}$ and similar pathological changes have been found in man. ${ }^{17}$ The pathological changes caused by total body irradiation at transplantation may contribute to the increased susceptibility to pulmonary infections found after bone marrow grafting. Lung function abnormalities resulting from pulmonary irradiation include reduced lung volumes and transfer factor for carbon monoxide for the first three months, with some improvement during the subsequent one to two years. ${ }^{151115}$

Although there have been several studies of changes in lung function after bone marrow transplantation, none has indicated whether these measurements are useful for monitoring patients' progress after transplantation and for alerting clinicians to the early development of pneumonitis. There is some evidence that patients who are investigated and treated early have a better prognosis than those presenting after several days or weeks of symptoms. ${ }^{18}$ After heart-lung transplantation, however, 
Table 1 Clinical details of patients studied: comparison of patients who developed pneumonitis with patients who did not develop pneumonitis after transplantation

\begin{tabular}{|c|c|c|c|}
\hline & $\begin{array}{l}\text { No pneumonitis } \\
(n=21)\end{array}$ & $\begin{array}{l}\text { Pneumonitis } \\
(n=18)\end{array}$ & $p$ \\
\hline Allogeneic transplant & 17 & 17 & NS \\
\hline Autologous transplant & 4 & 1 & NS \\
\hline Age range (years) & $11-40$ & $15-49$ & NS \\
\hline No of smokers or ex-smokers & 1 & $2 \star$ & NS \\
\hline \multicolumn{4}{|l|}{$\begin{array}{l}\text { Pretransplantation haematological diagnoses } \\
\text { (No of patients) }\end{array}$} \\
\hline Acute lymphoblastic leukaemia & 14 & 4 & $<0.01$ \\
\hline Acute myeloid leukaemia & 4 & 8 & NS \\
\hline Chronic granulocytic leukaemia & 3 & 6 & NS \\
\hline \multicolumn{4}{|l|}{ Average radiation dose to lungs } \\
\hline (cGy, median (range)) & $716(649-765)$ & $755(692-800)$ & 0.002 \\
\hline Received $<720$ cGy (n) & 12 & 3 & $<0.01$ \\
\hline
\end{tabular}

^Both ex-smokers, having stopped smoking more than six months before receiving their transplant. tion, day 0 being the day on which transplantation was performed) and total body irradiation with a single prescribed dose of $750 \mathrm{cGy}$ at a dose rate of $26 \mathrm{cGy} / \mathrm{min}$ in air on day 0 . A total of 14 patients received standard conditioning.

All patients with acute lymphoblastic leukaemia and patients receiving a mismatched transplant received high risk conditioning according to the Wisconsin modified protocol. This regimen comprised two doses of cyclophosphamide $45 \mathrm{mg} / \mathrm{kg}$ body weight on days -4 and -3 plus six doses of cytosine arabinoside $3 \mathrm{~g} / \mathrm{m}^{2}$ and total body irradiation as above. One patient received high risk conditioning with fractionated total body irradiation in three fractions of 276, 293, and $356 \mathrm{cGy}$.

The average radiation dose to the lungs ranged from 649 to $800 \mathrm{cGy}$.

lung function measurements have been found to be sensitive indicators of acute lung rejection and infection. ${ }^{19}$ We have investigated a group of patients with haematological malignancies treated with $T$ cell depleted bone marrow transplants to see whether pulmonary function measurements could be used to predict which patients would be at risk of pneumonitis. We have also used these measurements to investigate all patients complaining of breathlessness, whether or not they had abnormal physical signs in the chest or an abnormal chest radiograph, to determine whether abnormalities of lung function are sensitive indices of developing pneumonitis.

\section{Methods \\ PATIENTS}

Serial pulmonary function measurements were made in 39 patients with a haematological malignancy who had been treated with $T$ cell depleted allogeneic $(n=34)$ or autologous $(\mathrm{n}=5)$ bone marrow transplants. The pretransplant diagnoses and other details of the patients are given in table 1 . Eighteen of the patients subsequently developed pneumonitis. The treatment regimens used to induce remission varied between individuals but the drugs commonly used were daunorubicin, cytosine arabinoside, and 6-thioguanine for acute myeloid leukaemia; vincristine, prednisolone, daunorubicin, L-asparaginase, etoposide (VP16/213), thioguanine, methotrexate, and 6-mercaptopurine for acute lymphoblastic leukaemia; and busulphan or hydroxyurea or both for chronic granulocytic leukaemia. Thirty four patients received $\mathrm{T}$ cell depleted bone marrow from matched $(n=27)$ or mismatched $(\mathbf{n}=7)$ sibling donors. Five patients received autologous transplants.

\section{PRETRANSPLANT CONDITIONING}

Patients with acute myeloid leukaemia in first complete remission and all patients with chronic granulocytic leukaemia who received HLA matched transplants were given standard conditioning of two doses of cyclophosphamide $60 \mathrm{mg} / \mathrm{kg}$ body weight on days -4 and -3 (that is, four and three days before transplanta-

\section{LUNG FUNCTION MEASUREMENTS}

Lung function was measured by standard methods. FEV ${ }_{1}$ and FVC were measured with a dry bellows spirometer (Vitlograph Ltd), lung volumes were measured by the rebreathing helium dilution method (PK Morgan Ltd) and transfer factor for carbon monoxide (TLCO) was measured by the single breath carbon monoxide transfer test (PK Morgan Ltd). Spirometry and lung volume measurements were made at least three times and gas transfer measurements at least twice, until repeatable values were obtained. TLCO measurements were repeated until the difference between two values was less than $5 \%$.

Pulmonary function was measured in all patients before transplantation and six weeks, three months, six months, nine months, and one year after transplantation when possible. Additional measurements were made on patients complaining of shortness of breath.

Serial lung function measurements (including a pretransplant measurement) were made on 18 of the patients who later developed pneumonitis and compared with measurements made on 21 recipients of transplants in the same unit who did not develop pneumonitis at any time after transplantation. In addition, lung function was measured at the onset of a further 18 episodes of pneumonitis.

\section{STATISTICAL METHODS}

Results are expressed as means with standard deviations in parentheses. Comparisons between groups were made with the corrected $\chi^{2}$ test and means were compared by using the Student's $t$ test for unpaired data. We considered a p value below 0.05 to be significant.

\section{Results}

COMPARISON OF PATIENTS WHO DEVELOPED PNEUMONITIS WITH THOSE WHO DID NOT $\mathrm{FEV}_{1}$, TLCO, and lung volumes before transplantation did not differ between patients who developed pneumonitis and those who did not; mean (SD) FVC (\% predicted) was slightly higher in the pneumonitis group (104 (12)) than in the other patients $(93(17) ; \mathrm{p}<0.05)$. Six weeks and three months after transplantation all lung function measurements had fallen 
Figure 1 Serial measurements of forced vital capacity (FVC) in (A) 18 patients developing pneumonitis and $(B) 21$ patients not progressing to pneumonitis (mean values with standard deviation bars). $\mathrm{x} p<0.05 ; \star \star p<0.001$ (comparison with pretransplantation measurements). The dotted lines indicate the development of pneumonitis.

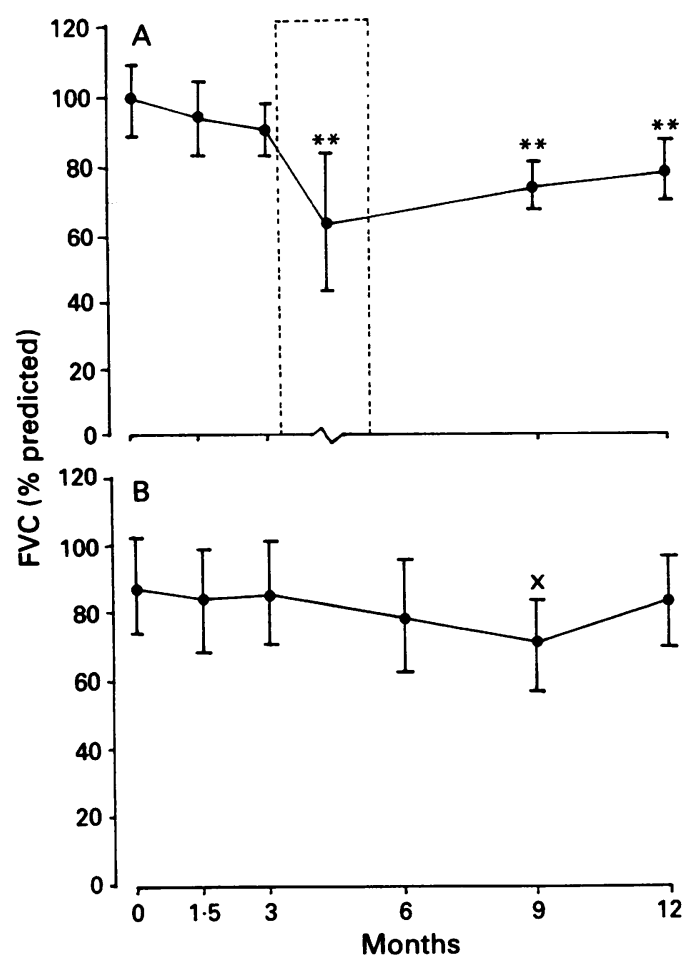

slightly in both groups but there were no differences in $\mathrm{FEV}_{1}$, FVC, or lung volumes between the two groups. TLCO, however, had fallen considerably more by six weeks and three months after transplantation in those who later developed pneumonitis. Results for FVC and TLCo are shown in figures 1 and 2. The mean (SD) TLCo at six weeks and three months as a percentage of the pretransplant value was 109 (38) and 96 (26) in the non-pneumonitis group and 71 (11) and 77 (7) in the pneumonitis group ( $p<0.01$ and $=0.01$ ) (fig 3). None of the patients showing a fall in TLCo six weeks after transplantation of less than $10 \%$ from the pretransplant value later developed pneumo-

Figure 2 Serial
measurements of carbon
monoxide transfer factor
(TLCO) in ( $A) 18$
patients developing
pneumonitis and (B) 21
patients not progressing to
pneumonitis (mean values
with standard deviation
bars). $\mathrm{Xp}<0.05$;
$\star \star p<0.001$ (comparison
with pre-transplantation
measurements). The
dotted lines indicate the
development of
pneumonitis.

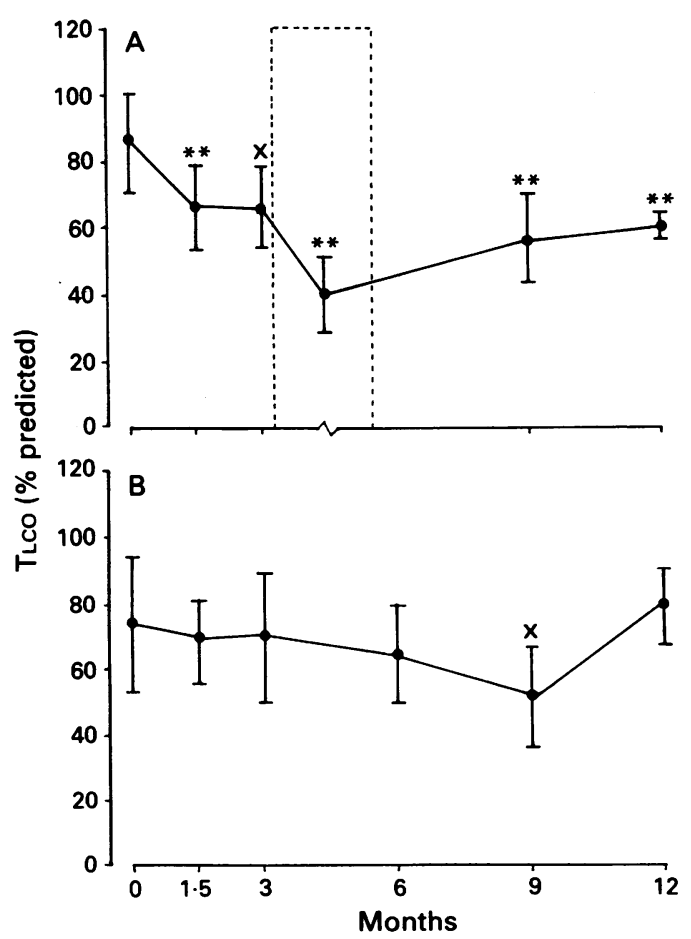

nitis, whereas 10 of the 15 patients with a fall of $10-30 \%$ in TLCO and all eight patients with a fall in TLCO of more than $30 \%$ six weeks after transplantation later developed pneumonitis.

At the onset of pneumonitis all measurements were significantly lower than three months after transplantation (figs 1 and 2, table 2). This occurred in all patients, even those with no abnormal signs at presentation or a normal chest radiograph. The TLCo fell to $20-59 \%$ of predicted normal values at the onset of pneumonitis, a significantly greater fall than the fall seen three and six months after transplantation in the patients who did not develop pneumonitis.

The patients who did not develop pneumonitis showed some abnormalities of lung function nine months after transplantation, but function had generally recovered by one year. The nine patients who recovered from pneumonitis showed some recovery of lung function but values usually differed significantly from pretransplantation measurements (figs 1-3).

\section{RELATION OF LUNG FUNCTION CHANGES TO} SYMPTOMS

Despite the fall in TLCo six weeks and three months after transplantation in the patients who subsequently developed pneumonitis, none of the patients had any important symp-

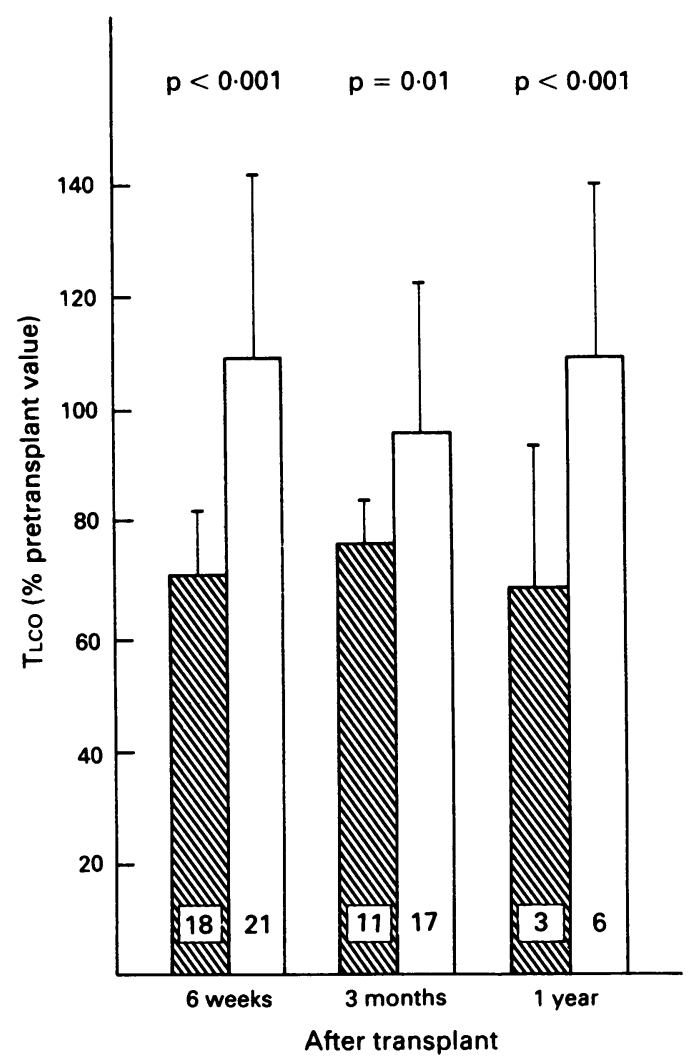

Figure 3 Fall in carbon monoxide gas transfer (TLCO) at six weeks and three months in patients developing pneumonitis (hatched blocks) and patients not developing pneumonitis (open blocks). There was a significant difference between these two groups even before the development of symptoms of pneumonitis. TLCO in survivors of pneumonitis showed some recovery but remained low at one year after transplantation. The numbers of patients in each group are shown in the blocks; these numbers decreased with time, as a result both of death and of non-attendance (patients having been drawn from across Britain and from overseas). 
Table 2 Mean (SD) lung function measurements in patients who developed pneumonitis

\begin{tabular}{llcl}
\hline & $\begin{array}{l}\text { Before } \\
\text { transplant }\end{array}$ & $\begin{array}{l}\text { Six weeks after } \\
\text { transplant } \\
(\text { mean }(S D)) \% \text { pred) }\end{array}$ & $\begin{array}{l}\text { At onset of } \\
\text { pneumonitis }\end{array}$ \\
\hline FEV & $105(16)$ & $96(14)$ & $67(20)^{\star \star}$ \\
FVC & $104(12)$ & $98(12)$ & $65(21)^{\star \star}$ \\
TLC & $106(8)$ & $102(9)$ & $74(14)^{\star \star}$ \\
TLCO & $87(15)$ & $67(15)^{\star \star}$ & $41(12)^{\star \star}$ \\
\hline
\end{tabular}

${ }^{\star \star} \mathrm{p}<0.001$ : value compared with pretransplant measurements.

$\mathrm{FEV}_{1}$ - forced expiratory volume in one second; FVC-forced vital capacity; TLC - total lung capacity; TLCO-transfer factor for carbon monoxide.

toms at the time to prompt further investigations and chest radiographs at these times were normal or unchanged. At the onset of pneumonitis shortness of breath and fever were the most frequent symptoms; abnormal signs in the chest were frequent but not universal and some patients still had a normal chest radiograph (table 3). Most patients developed pneumonitis three to six months after transplantation. Some patients developed a second episode some months later. The time between the first noted fall in TLCO and the development of pneumonitis varied from one to 32 weeks (mean (SD) 9.6 (8.1) weeks). Of 36 episodes of pneumonitis, 29 were associated with intrapulmonary infection identified by culture of bronchoalveolar lavage fluid. In 13 episodes cytomegalovirus was identified by detection of early antigenic fluorescent foci and culture. Other organisms found were Pneumocystis carinii in two patients, fungi (Aspergillus fumigatus and Candida albicans) in seven patients, bacteria in two patients, and mixed infections in five patients.

AVERAGE DOSE OF RADIATION TO THE LUNGS

The patients who developed pneumonitis after bone marrow transplantation had in general received a higher average dose of radiation to the lungs (median 755, range 692-800 cGy) than the patients who did not develop pneumonitis (median 716, range 649-765 cGy; $\mathrm{p}=0.002$ ). In the pneumonitis group only three of 18 patients received less than $720 \mathrm{cGy}$ radiation to the lungs, compared with 12 of 21 patients who did not progress to pneumonitis $(\mathrm{p}<0.01)$.

Table 3 Symptoms and signs developing in 18 patients with pneumonitis after bone marrow transplantation

\begin{tabular}{lllll}
\hline & \multicolumn{2}{l}{ Number of patients } & & \\
\cline { 2 - 5 } $\begin{array}{l}\text { Six weeks after } \\
\text { transplant }\end{array}$ & $\begin{array}{l}\text { At onset of } \\
\text { pneumonitis }\end{array}$ & 17 & $\begin{array}{l}\text { After pneumonitis } \\
\text { (9 survivors) }\end{array}$ \\
\hline $\begin{array}{l}\text { No new specific } \\
\text { symptoms (all } \\
\text { patients) }\end{array}$ & Shortness of breath & 18 & $\begin{array}{l}\text { Less shortness of breath but } \\
\text { more than before transplant }\end{array}$ & 5 \\
& Fever & 11 & Breathing as before transplant & 2 \\
$\begin{array}{l}\text { Radiograph normal } \\
\text { or unchanged (all } \\
\text { patients) }\end{array}$ & Cough & 13 & & \\
& $\begin{array}{l}\text { Chest signs } \\
\text { Abnormal radiograph }\end{array}$ & 16 & & \\
\hline
\end{tabular}

RELATION OF PNEUMONITIS TO DIAGNOSIS, TREATMENT, AGE, AND SMOKING

There were patients with acute myeloid leukaemia, acute lymphoblastic leukaemia, and chronic granulocytic leukaemia in both groups but a slight preponderence of patients with acute lymphoblastic leukaemia in the group who did not develop pneumonitis (table 1). A similar range of chemotherapeutic agents had been used in the two groups. The age ranges of the two groups were also similar. Very few patients smoked and there was no excess of smokers in the pneumonitis group.

\section{Discussion}

In this study lung function measurements six weeks after transplantation were abnormal in the patients who subsequently developed pneumonitis, and they may have a role as an early indicator of pneumonitis. The abnormality in gas transfer in these patients was found six weeks after transplantation, suggesting that lung damage sustained at or around the time of transplantation is likely to play a part in the later development of pneumonitis.

Irradiation causes pneumonitis 6-12 weeks after radiotherapy and was first described by Bergonie and Tessier in $1898 .^{20}$ Lung function tests show reduced lung volumes and TLCO. ${ }^{16}$ In a study by Weiner and Dicke ${ }^{21}$ the incidence of pneumonitis was $32 \%$ among the recipients of transplants conditioned with irradiation but only $8 \%$ among those who did not receive irradiation. Most of the patients in our study who developed pneumonitis had received an average radiation dose to the lungs above 720 cGy whereas most of the patients who did not develop pneumonitis had received a lower dose. The time interval between total body irradiation and the development of pneumonitis in most patients is consistent with a low grade radiation process. This cannot, however, be the whole explanation as the lungs were infected with opportunist organisms in 29 of the 36 patients with pneumonitis. The development of pneumonitis was not related to pretransplant conditioning in a study by Wingard et $a l^{22}$ but was much more likely with allogeneic than with autologous transplants. In their study ${ }^{22}$ a quarter of the patients who had transplants for aplastic anaemia developed pneumonitis despite receiving no total body irradiation in the conditioning regimen. Nevertheless, patients with both allogeneic and autologous transplants who did receive total body irradiation as part of pretransplantation conditioning had a higher incidence of cytomegalovirus pneumonitis $(18 \%$ with allogeneic and $6 \%$ with autologous transplants) than recipients of allogeneic and autologous transplants who were not irradiated $(13 \%$ and $3 \%)^{22}$ This suggests that radiation has a role in the development of pneumonitis but is not the only culprit. Radiation damage received at transplantation may therefore predispose patients to pneumonitis and may make the lungs more susceptible to infection by opportunist organisms. As most episodes of 
pneumonitis were associated with intrapulmonary infections, pneumonitis is unlikely to have been simply a late manifestation of radiation pneumonitis. Furthermore, the reduction in TLCo found six weeks after transplantation was unlikely to have been due to chronic low grade infection as it occurred in all patients who later developed pneumonitis, including those in whom no cause of infection was found.

Although infectious organisms are frequently found in the lungs of patients with pneumonitis, there is a growing body of evidence, both from animal and from human studies, that pneumonitis is an immunopathological condition and not simply a result of overwhelming opportunist infection. ${ }^{23-25} \mathrm{We}$ have found aggressive humoral and cellular immune responses in the lungs of recipients of bone marrow transplants with pneumonitis ${ }^{2627}$ and possibly this immune response causes a reduction in TLCo early after transplantation as a hypersensitivity reaction following total body irradiation. This is supported by our observation that the patients who developed pneumonitis had received higher doses of radiation to the lungs than the patients who did not. Radiation may alter the expression of host antigens on cells in the lung interstitium, resulting in the enhanced cytotoxic response seen in autoimmune and graft versus host reactions ${ }^{28}$ and leading to progressive lung damage. This may be accelerated in the presence of an acute opportunist infection.

This study shows that measurements of lung function, especially of TLCO, are sensitive indices of pulmonary disease following bone marrow transplantation. There is a group of patients in whom an increased risk of pneumonitis can be predicted, and pulmonary function measurements can be used at the onset of pneumonitis as an early indication that there is a problem. The fall in TLCo usually occurs before chest radiographic abnormalities are seen and before the appearance of some clinical signs. Spirometric measurements fell significantly at the onset of pneumonitis, making it easy to make a quick assessment of any patient complaining of breathlessness after bone marrow transplantation. Any appreciable change in the measurements should stimulate further investigation as patients with pulmonary infections associated with pneumonitis who are treated early in the course of their disease have a better chance of survival than those treated later. ${ }^{18}$

1 Depledge MH, Barrett A, Powles RL. Lung function after bone marrow grafting. Int J Radiat Oncol Biol Phys 1983;9:145-51.

2 Ginsberg SJ, Comis RL. The pulmonary toxicity of antineoplastic agents. Semin Oncol 1982;9:34-51.

3 Louie S, Lillington GA. Low dose methotrexate pneumonitis in rheumatoid arthritis. Thorax 1986;41:703-4.

4 Ernst P, Sorensen PG. Cytotoxic lung damage. Exp Haematol 1984;12(suppl 15):8-11.

5 Barrett A, Depledge MH, Powles RL. Interstitial pneumonitis following bone marrow transplantation after low dose total body irradiation. In J Radiat Oncol Biol Phys 1983;9:1029-33.

6 Wyatt SE, Nunn P, Hows JM, Yin J, Hayes ML, Catovsky $\mathrm{D}$, et al. Airways obstruction associated with graft versus host disease after marrow transplantation. Thorax 1984; 39:887-94.

7 Link H, Reinhard U, Blaurock M, Ostendorf D. Lung function changes after allogeneic marrow transplantation. Thorax 1986;41:508-12.

8 Springmeyer SC, Flournoy N, Sullivan KM, Storb R, Thomas ED. Pulmonary function changes in long-term survivors of allogeneic marrow transplantation. In: Gale $\mathrm{RP}$, ed. Recent advances in bone marrow transplantation. New York: Liss, 1983:343-53.

9 Serota FT, August CS, Koch PA, Fox W, D'Angio GJ. Pulmonary function in patients undergoing bone marrow Pulmonary function in patients undergoing bone marr

10 Link H, Ostendorf P, Werner P, Reinhard U, Walter E, Fischbach $\mathrm{H}$, et al. Pulmonary complications after allogenic bone marrow transplantation: The Tubingen experience. Exp Haematol 1984;12(suppl 15):21-2.

11 Clark JG, Crawford SW, Madtes DK, Sullivan KM. Obstructive lung disease after allogeneic marrow transplantation. Clinical presentation and course. Ann Intern Med 1989;111:368-76.

12 Rosenberg ME, Vercellotti GM, Snover DC, Hurd D, McGlave P. Bronchiolitis obliterans after bone marrow transplantation. Am J Haematol 1985;18:325-8.

13 Holland HK, Wingard JR, Beschorner WE, Saral R, Santos GW. Bronchiolitis obliterans in bone marrow transplantation and its relationship to chronic graft-versus-host disease and low serum IgG. Blood 1988;72:621-7.

14 Ralph DD, Springmeyer SC, Sullivan KM, Hackman RC, Storb R, Thomas ED. Rapidly progressive airflow obstruction in marrow transplant recipients-possible association between obliterative bronchiolitis and chronic graft versus host disease. Am Rev Respir Dis 1984; 129:641-4.

15 Gross NJ. Pulmonary effects of radiation therapy. Ann Intern Med 1977;86:81-92.

16 Barrett A. Relationship of irradiation to pulmonary complications. Exp Haematol 1984;12(suppl 15):6-7.

17 Liebow AA, Warren S, DeCoursey E. Pathology of atomic bomb casualties. Am J Pathol 1949;25:853-67.

18 Milburn HJ, Prentice HG, du Bois RM. The role of bronchoalveolar lavage in the evaluation of interstitial pneumonitis in bone marrow transplant recipients. Thorax 1987;42:766-72.

19 Otulana BA, Higenbottam T, Scott J, Clelland C, Igbaoka G, Wallwork J. Lung function associated with histologically diagnosed acute lung rejection and pulmonary infection in heart-lung transplant patients. Am Rev Respir Dis 1990;142:329-32.

20 Bergonie J, Tessier P. Sur l'actions des rayons X sur la tuberculose. Archives d'Electric Médecine 1898;6:334-60.

21 Weiner RS, Dicke KA, for the Advisory Committee of the International Bone Marrow Transplant Registry. Risk factors for interstitial pneumonitis following allogeneic bone marrow transplantation for severe aplastic anaemia: a preliminary report. Transpl Proc 1987;24:2639-42.

22 Wingard JR, Mellits D, Sostrin MB, Chen D Y-H, Burns WH, Santos GW, et al. Interstitial pneumonitis after allogeneic bone marrow transplantation: nine-year experience at a single institution. Medicine 1988;67: experience

23 Shepp DH, Dandliker PS, de Miranda P, Burnette TC, Cederberg DM, Kirk LE, et al. Activity of 9-(2hydroxymethyl)-ethoxymethyl)-guanine in the treatment of cytomegalovirus pneumonia. Ann Intern Med 1985;103: 368-73.

24 Shanley JD, Pomeroy C, Via CS, Shearer GM. Interstitial pneumonitis during murine cytomegalovirus infection and graft versus host reaction: effect of ganciclovir therapy. $J$ Inf Dis 1988;158:1391-4.

25 Grundy JE, Shanley JD, Griffiths PD. Is cytomegalovirus interstitial pneumonitis an immunopathological condition? Lancet 1987;ii:997-9.

26 Milburn HJ, Grundy JE, du Bois RM, Prentice HG, Griffiths PD. The humoral immune response in the lung of bone marrow transplant recipients with interstitial pneumonitis. Clin Exp Immunol 1988;72:309-14.

27 Milburn HJ, du Bois RM, Prentice HG, Poulter LW. Pneumonitis following bone marrow transplantation results from a local immune response. Clin Exp Immunol 1990;81:232-7.

28 Lum LG, Orcutt-Thordarson N, Seigeuret MC, Storb R. The regulation of immunoglobulin synthesis after marrow transplantation. IV: T4 and T8 subset function in patients with chronic graft-versus-host disease. J Immunol 1982;129:113-7. 